\section{CASE OF MALFORMATION.}

By J. H. Spencer, Esq., Hallaton.

I was called to Mary Lee, after a midwife, and found what I considered placenta prævia, but which turned out to be what I may call liver presentation; the liver with the stomach and part of the intestines being external. There was also singular malformation of the chest, with spina bifida. There was not a trace of organs of generation, nor of anus; and not a vestige of funis could be found. No doubt, from the ragged state of the liver and placenta, they were in close contact, and thus had the child been even well nourished, being quite of the average weight.

The mother had suffered a good deal the fortnight preceding her accouchement; no donbt from the dragging at the placenta, which was firmly adherent. The child was dead, but had not long been so.

\section{LE'TTERS AND COMMUNICATIONS.}

Letters or communications for the Journar should be addressed to Dr. Wynter, Coleherne Court, Old Brompton, S.W.

Letters regarding the business aepartment of the Journal, and corrected proofs, should be sent to 3\%, Great Queen Street, Lincoln's Inn Fields, W.C.

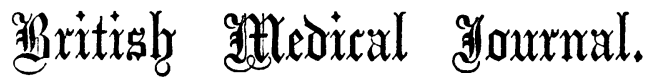

\section{SATURDAY, SEPTEMBER 10тн, 1859.}

\section{THE REPRIEVE OF SMETHURST.}

THE reprieve of Smethurst, so confidently anticipated by the whole country, has taken place as a matter of course. If he had been hanged, there would no longer have been safety for any medical man who waited upon the death-bed of his own wife, and was more than ordinarily attentive to her.

For Smethurst individually we care little; but it is of the utmost importance that human life should not henceforth be at the mercy of bungling experimenters, imperfect medical observers, and ignorant and under-educated jurymen.

It must have struck our readers that, in the present instance, the real trial of the prisoner took place after the verdict of death had been pronounced, and the judge had, with all due solemnity, put on the black cap. Immediately the evidence had been disseminated throughout the length and breadth of the country, then the real trial of Smethurst commenced. The letters which appeared in the public papers, from a hundred different quarters, formed the true appeal of the prisoner against the decision of the jury; and the result was its reversal. Henceforth the public will not rest satisfied, in trials of life and death, where nice points of scientific evidence are discussed, with the verdict of an ill-informed jury, led by a toopartial judge. If we must not lay hands on the venerable "twelve good men and true", it is clear we cannot go on without the institution of some court of appeal; unless we choose to rest satisfied with that irregular court of appeal, the public press, which in this instance has so unceremoniously put aside judge and jury, and brought its powerful force to bear upon the judge at Downing Street.

If medicine has had the misfortune of leading human life to the verge of the gallows, it is at least satisfactory to know that to medicine we owe our escape from such a public disaster. We think there can be little doubt on the professional mind, that Smethurst owes his life to the evidence given with such earnestness and force by Dr. Tyler Smith. His letter in the Times at once arrested public attention, and compelled authorities to listen. We may state that, from the moment of its appearance, the Home Secretary was in constant communication with him; and it was on his final statement, given in the Times, that there was nothing in the symptoms of Isabella Bankes incompatible with Smethurst's innocence, that the reprieve was decided upon. In a trial in which, we regret to say, the spirit of partisanship, and the instinct of man-hunting have been so very apparent, it must be at least satisfactory to our distinguished associate, that his instincts and his advocacy have been on the side of justice and mercy.

As there is a very general opinion that Smethurst did the deed, although the evidence was totally insufficient to convict him, we may, perhaps, be permitted to state that this opinion seems to be founded on the alleged fact that no fewer than three medical men, without communicating to each other their suspicions, came to the conclusion that Miss Bankes was being poisoned; and on the statement of the judge, made in his charge, that " no answer had been given to the main point of the prosecution, that no medicine whatever had the slightest effect upon the malady under which the deceased was suffering." With respect to the first statement, we think the shorthand evidence clearly proves that the medical men did communicate their suspicions to each other. It is far from our purpose to say that these gentlemen have, in total disregard of their oaths, told untruths; but there are a hundred modes of communicating suspicions without the use of words, and, we may add, quite unconsciously to the persons themselves-an expression of face would be sufficient. Indeed, we may say that, in our opinion, it would be very difficult to conceal a suspicion of this kind-in manner, at least, it would betray itself. That Dr. Julius did lead Dr. Bird to suspect poisoning, we may infer from the following passage in the evidence of the latter :-

"Mr. Serjeant Parry. Q. Did you ever form that opinion" (of slow poisoning by arsenic) " before Dr. Julius suggested it to you? A. I did not. He first suggested it to me, and then I agreed with him."

Here it is clear that, as far as slow poisoning by arsenic was concerned, Dr. Julius did communicate his suspicions to his partner. And can we conceive Dr. Todd coming down to this mysterious case without extracting some opinion from the physician in attendance? The only thing which puzzles us here, however, is to reconcile Dr. Todd's belief that he was treating a person who was being slowly poisoned, with the fact that he ordered her copper pills! This prescription would seem to imply that he thought she was suffering under dysen. tery. If he suspected poison, why did he order that which would only add fuel to the fire? Our own impression is, that there was a vague understanding between all of the medical men in attendance, which did not take a definite shape until Dr. Taylor gave his opinion; and then, to their retrospective eyes, all was clear.

With regard to the judge's extraordinary statement, we can only say, that there is nothing more common than for dysentery to run its course in defiance of all the skill of all the doctors in the world. 